\title{
Effect of substrate crystallographic orientation on wettability and adhesion in several representative systems
}

\author{
P. Shen, H. Fujii*, K. Nogi \\ Joining and Welding Research Institute, Osaka University, 11-1 Mihogaoka Ibaraki, Osaka 567-0047, Japan
}

\begin{abstract}
This paper describes the effect of substrate crystallographic orientation on the wettability and adhesion and explains the related mechanisms. Four representative systems are exemplified to show this effect. The effect, in nature, is determined by the characteristics of the atoms terminated at the substrate surface, which include their type, quantity and bond strength with the molten material atoms.
\end{abstract}

(C) 2004 Elsevier B.V. All rights reserved.

Keywords: Wetting; Contact angle; Adhesion; Crystallographic orientation

\section{Introduction}

A comprehensive understanding of the factors responsible for the wettability and adhesion of a solid by a liquid metal is not only of scientific interest but also of considerable technological importance. This is particularly important for the fabrication of metal-ceramic composites, joints and thin-film materials. It has been realized that the wettability of a solid by a liquid is not only determined by the thermodynamic characteristics of the system such as solubility and reactivity, but also affected by some external factors such as temperature, working atmosphere (especially oxygen partial pressure), impurities and substrate surface conditions including surface roughness, crystallographic orientation and adsorption, etc.

To the best of our knowledge, there have not been many investigations on the effect of the crystallographic orientation despite the fact that the knowledge itself plays an important role in understanding and controlling the physical or chemical processes such as thin-film/crystal epitaxial growth and adhesion. In this article, we present such a study mainly based on our previous and recent experimental results with an emphasis on the related mechanisms.

\footnotetext{
* Corresponding author. Tel.: +81-6-6879-8653; fax: +81-6-6879-8689. E-mail addresses: shenping@jwri.osaka-u.ac.jp (P. Shen), fujii@jwri.osaka-u.ac.jp (H. Fujii).
}

\section{Effect of crystallographic orientation}

\subsection{In strong-interaction single-component systems}

As an illustration, we use the results from Naidich et al. [1] on the wettability of the different oriented faces of germanium (Ge) single crystals by its own melt, as shown in Table 1. The work of adhesion, $W_{\mathrm{ad}}$, was calculated from the Young-Dupré equation:

$W_{\mathrm{ad}}=\sigma_{\mathrm{sg}}+\sigma_{\mathrm{lg}}-\sigma_{\mathrm{sl}}=\sigma_{\mathrm{lg}}(1+\cos \theta)$

where $\sigma_{\mathrm{sg}}, \sigma_{\mathrm{lg}}$ and $\sigma_{\mathrm{sl}}$ are the solid-gas, liquid-gas and solid-liquid interfacial free energies, respectively. Note that the contact angle and the work of adhesion vary with the crystallographic orientation of the Ge substrates. The lowest contact angle and the highest work of adhesion appear on the face with the smallest atomic density and the largest interplanar spacing, indicating that the wettability and the adhesion on the less close-packed faces are better than those on the closer-packed faces. This may be understood from the surface physics of metals and the nature of the adhesion at the interface as well as the cohesion in the bulk crystal. As is known, during the formation of a new surface, energy is required to break the bonds between atoms either in the bulk (i.e., the origin of the cohesion) or at the interface (i.e., the origin of the adhesion). The energies, both the cohesion and the adhesion, depend on the number of broken bonds. The most stable surface has the smallest number of broken bonds. It is also the most compact surface, on which the coordination number of the atoms is not significantly reduced 
Table 1

Contact angle and work of adhesion of Ge single crystals by its own melt [1]

\begin{tabular}{|c|c|c|c|c|}
\hline Crystal & Face & Contact angle $\theta\left({ }^{\circ}\right)$ & Work of adhesion, $W_{\mathrm{ad}}\left(\mathrm{mJ} / \mathrm{m}^{2}\right)$ & Some physical characteristics of crystals \\
\hline \multirow[t]{3}{*}{ Germanium } & $\left(\begin{array}{lll}1 & 1 & 1\end{array}\right)$ & $30 \pm 3$ & 1194 & $d=1.4113, \rho=14.42 \times 10^{14}$ \\
\hline & $\left(\begin{array}{lll}1 & 1 & 0\end{array}\right)$ & $17 \pm 3$ & 1252 & $d=2.0224, \rho=8.82 \times 10^{14}$ \\
\hline & $\left(\begin{array}{llll}1 & 0 & 0\end{array}\right)$ & $9 \pm 4$ & 1272 & $d=2.4467, \rho=6.24 \times 10^{14}$ \\
\hline
\end{tabular}

$d=$ interplanar spacing $(\AA) ; \rho=$ reticular atom density $\left(\right.$ atoms $\left./ \mathrm{cm}^{2}\right)$.

[2]. In other words, the surface atoms are still relatively tightly bound by the bulk ones. As a result, the liquid on its own closest-packed surface develops a relatively weaker adhesion at the interface despite the fact that the atomic density at the solid surface is the highest.

\subsection{In weak-interaction metal/carbon systems}

An opposite effect of the crystallographic orientation as well as the surface atomic density on the wettability and adhesion was found by Nogi et al. [3] and Dezellus and Eustathopoulos [4] in their respective studies of the non-reactive metal $(\mathrm{Sn}, \mathrm{Pb}, \mathrm{Bi}, \mathrm{Ag}, \mathrm{Cu}$ and $\mathrm{Au}) /$ carbon systems. These systems have a common characteristic, i.e., the liquid metals are inert to carbon, neither forming carbides nor significantly dissolving carbon. The predominant interactions at the liquid-solid interface are van der Waals dispersion forces, which can be expressed as [4]

$E_{\mathrm{VDW}}=-\frac{k \pi \rho_{1} \rho_{2}}{12 r^{2}}$

where $k$ is the constant of the atom-atom pair potential, depending on the nature of the atoms, $\rho_{1}$ and $\rho_{2}$ are the numbers of atoms per unit volume at the liquid-solid interface, and $r$ is the separation distance between the two surfaces. Since the van der Waals force is directly proportional to the atomic densities of the contact phases, the wettability and the adhesion are essentially dependent on the atomic density of the substrate surface. As seen from Table 2, the lowest contact angle and the highest work of adhesion are displayed on the most compact (1 1 1 1) face of diamond for all the metals except for $\mathrm{Ag}$. The results of $\mathrm{Au}$ and $\mathrm{Cu}$ on the pseudo-monocrystalline graphite and vitreous carbon substrates from Dezellus and Eustathopoulos [4] also indicate that the wettability and the adhesion increase with the atomic density of the substrate surface. As a consequence, it might be reasonable to expect that the wettability and adhesion on the different oriented faces of diamond single crystals should be in the order of $\left(\begin{array}{lll}1 & 1 & 1\end{array}\right)>\left(\begin{array}{lll}1 & 1 & 0\end{array}\right)>\left(\begin{array}{lll}1 & 0 & 0\end{array}\right)$. AFM measurements of the interactions between the diamond surfaces and a $\mathrm{Si}_{3} \mathrm{~N}_{4}$ probe further demonstrated this prediction [5]. Deviations from this order (as reflected in Table 2) may result from the influence of atmospheric $\left(\mathrm{H}_{2}\right)$ adsorption on the diamond surface and the surface structural transformation of diamond into graphite at temperatures above approximately $1000 \mathrm{~K}[3,5]$.

\subsection{In weak-interaction metal/oxide systems}

Table 3 lists the results of the contact angle and the work of adhesion of some non-reactive metals $(\mathrm{Bi}, \mathrm{Pb}, \mathrm{Sn})$ on three different faces of $\mathrm{MgO}$ single crystals. It can be seen that the best wettability and the highest adhesion of the $\mathrm{MgO}$ single crystals by all the liquid metals are on the (100) face, whereas the worst wettability and the lowest adhesion are on the (110) face. (100) is the most compact plane for the $\mathrm{MgO}$ crystal, however, the quantity (or density) of oxygen ions $\left(\mathrm{NO}^{2-}\right)$ on the three faces is in the sequence of $\left(\begin{array}{lll}1 & 1 & 1\end{array}\right)>\left(\begin{array}{lll}1 & 0 & 0\end{array}\right)>\left(\begin{array}{ll}1 & 10\end{array}\right)$ (see Table 4) providing that the atomic configuration at the surface is the same as that in the bulk. Obviously, the number of oxygen ions alone cannot account for the order of the contact angle and the work of adhesion. Other factors must be taken into account. Nogi et al. [6] explained it from the interactions (coulomb force, $F$ ) between the top-layer $\mathrm{O}^{2-}$ and the second layer $\mathrm{Mg}^{2+}$ at the $\mathrm{MgO}$ surface. The stronger are the $\mathrm{O}-\mathrm{Mg}$ interactions towards the substrate bulk, the weaker is the adhesion at the interface. Therefore, they employed the value of $\mathrm{NO}^{2-} / F$ to evaluate the function of the crystallographic orientation. The larger is the $\mathrm{NO}^{2-} / F$, the higher is the adhesion. As listed in Table 4, the value of $\mathrm{NO}^{2-} / F$ for the three faces is in the order of $\left(\begin{array}{lll}1 & 0 & 0\end{array}\right)>\left(\begin{array}{lll}1 & 1 & 1\end{array}\right)>\left(\begin{array}{lll}1 & 1 & 0\end{array}\right)$, thus, it was suggested that the $\mathrm{NO}^{2-} / F$ might explain the effect of the crystallographic orientation. Despite the fact that this explanation seems reasonable, the later AFM observation on the $\mathrm{MgO}$ single crystal surfaces indicates that the surface structures are quite different from the bulk ones. The number of oxygen atoms on the three $\mathrm{MgO}$ surfaces is in the order of $\left(\begin{array}{lll}1 & 1 & 1\end{array}\right)>\left(\begin{array}{lll}1 & 1 & 0\end{array}\right)>$ (1 000$)$ [7]. Therefore, the $\mathrm{NO}^{2-} / F$ is not the sole decisive factor. Another possible factor is the interactions between the liquid metal atoms and the surface $\mathrm{Mg}$ atoms. By referring to the phase diagrams of the $\mathrm{Bi}-\mathrm{Mg}, \mathrm{Pb}-\mathrm{Mg}$ and $\mathrm{Sn}-\mathrm{Mg}$ binary alloys and their thermodynamic data such as heat of formation $(\Delta H)$ and partial molar Gibbs energies $\left(\Delta \bar{G}_{\mathrm{Mg}}\right.$ and $\left.\Delta \bar{G}_{\text {metal }}\right)$ [8], the interactions between the metal atoms and the substrate $\mathrm{Mg}$ atoms, resulting from either the dissolution or formation of an intermetallic compound, cannot be completely neglected. Since the number of $\mathrm{Mg}$ atoms at the $(100) \mathrm{MgO}$ face is more than that at the other two faces, it is possibly responsible for the lowest contact angle and the highest work of adhesion on the (1 00 ) face. 
Table 2

Contact angle and work of adhesion of carbons (diamond, pseudo-monocrystalline graphite and vitreous carbon) by non-reactive melts (Bi, $\mathrm{Pb}, \mathrm{Sn}, \mathrm{Ag}$, $\mathrm{Cu}$ and $\mathrm{Au})$

\begin{tabular}{|c|c|c|c|c|c|}
\hline Metal & Substrate & $\begin{array}{l}\text { Crystal face or some } \\
\text { properties }\end{array}$ & Contact angle $\theta\left(^{\circ}\right)$ & $\begin{array}{l}\text { Work of adhesion, } \\
W_{\mathrm{ad}}\left(\mathrm{mJ} / \mathrm{m}^{2}\right)\end{array}$ & $\begin{array}{l}\text { Experimental } \\
\text { conditions }\end{array}$ \\
\hline \multirow[t]{3}{*}{$\mathrm{Bi}[3]$} & \multirow[t]{3}{*}{ Diamond single crystals } & $\left(\begin{array}{lll}1 & 1 & 1\end{array}\right)$ & 98 & 301 & $T=853 \mathrm{~K}$ \\
\hline & & $\left(\begin{array}{lll}1 & 1 & 0\end{array}\right)$ & 106 & 253 & $\mathrm{H}_{2}$ atmosphere \\
\hline & & $\left(\begin{array}{lll}1 & 0 & 0\end{array}\right)$ & 113 & 213 & \\
\hline \multirow[t]{3}{*}{$\mathrm{Pb}[3]$} & \multirow[t]{3}{*}{ Diamond single crystals } & $\left(\begin{array}{lll}1 & 1 & 1\end{array}\right)$ & 101 & 352 & $T=873 \mathrm{~K}$ \\
\hline & & $\left(\begin{array}{lll}1 & 1 & 0\end{array}\right)$ & 117 & 234 & $\mathrm{H}_{2}$ atmosphere \\
\hline & & $\left(\begin{array}{lll}1 & 0 & 0\end{array}\right)$ & 110 & 279 & \\
\hline \multirow[t]{3}{*}{ Sn [3] } & \multirow[t]{3}{*}{ Diamond single crystals } & $\left(\begin{array}{lll}1 & 1 & 1\end{array}\right)$ & 130 & 180 & $T=1023 \mathrm{~K}$ \\
\hline & & $\left(\begin{array}{lll}1 & 1 & 0\end{array}\right)$ & 136 & 142 & $\mathrm{H}_{2}$ atmosphere \\
\hline & & $\left(\begin{array}{lll}1 & 0 & 0\end{array}\right)$ & 133 & 160 & \\
\hline \multirow[t]{3}{*}{ Ag [3] } & \multirow[t]{3}{*}{ Diamond single crystals } & $\left(\begin{array}{lll}1 & 1 & 1\end{array}\right)$ & 147 & 146 & $T=1273 \mathrm{~K}$ \\
\hline & & $\left(\begin{array}{lll}1 & 1 & 0\end{array}\right)$ & 103 & 700 & $\mathrm{H}_{2}$ atmosphere \\
\hline & & $\left(\begin{array}{lll}1 & 0 & 0\end{array}\right)$ & 135 & 265 & \\
\hline \multirow[t]{5}{*}{$\mathrm{Au}[3,4]$} & \multirow{3}{*}{ Diamond single crystals } & $\left(\begin{array}{lll}1 & 1 & 1\end{array}\right)$ & $110(0 \mathrm{~s})-134(3.6 \mathrm{ks})^{\mathrm{a}}$ & $720-334$ & $T=1373 \mathrm{~K}$ \\
\hline & & $\left(\begin{array}{lll}1 & 1 & 0\end{array}\right)$ & 151 & 137 & $\mathrm{H}_{2}$ atmosphere \\
\hline & & $\left(\begin{array}{lll}1 & 0 & 0\end{array}\right)$ & 151 & 137 & $(0.133 \mathrm{~Pa})$ \\
\hline & Vitreous carbon & $\rho=1.50-1.55^{\mathrm{b}}$ & $135 \pm 2$ & 338 & $T=1373 \mathrm{~K}$ \\
\hline & Pseudo-monocrystal & $\rho=2.255-2.266$ & $119 \pm 2$ & 595 & Vacuum, $10^{-5} \mathrm{~Pa}$ \\
\hline \multirow[t]{2}{*}{$\mathrm{Cu}[4]$} & Vitreous carbon & $\sigma_{\mathrm{sg}}=32 \pm 2$ & $139 \pm 2$ & 319 & $T=1373 \mathrm{~K}$ \\
\hline & Pseudo-monocrystal & $\sigma_{\mathrm{sg}}=151 \pm 38$ & $122 \pm 2$ & 611 & Vacuum, $10^{-5} \mathrm{~Pa}$ \\
\hline
\end{tabular}

a The contact angle changes with time due to graphitization of diamond.

b $\rho=$ density $\left(\times 10^{3} \mathrm{~kg} / \mathrm{m}^{3}\right)$.

Table 3

Contact angle and work of adhesion of $\mathrm{MgO}$ single crystals by $\mathrm{Bi}, \mathrm{Pb}$ and $\mathrm{Sn}$ melts [6]

\begin{tabular}{|c|c|c|c|}
\hline Metal & Crystal face & $\begin{array}{l}\text { Contact } \\
\text { angle, } \theta\left(^{\circ}\right)\end{array}$ & $\begin{array}{l}\text { Work of adhesion, } \\
W_{\text {ad }}\left(\mathrm{mJ} / \mathrm{m}^{2}\right)\end{array}$ \\
\hline \multirow[t]{3}{*}{$\mathrm{Bi}$} & $\left(\begin{array}{lll}1 & 1 & 1\end{array}\right)$ & 148 & 52 \\
\hline & $\left(\begin{array}{lll}1 & 1 & 0\end{array}\right)$ & 155 & 32 \\
\hline & $\left(\begin{array}{lll}1 & 0 & 0\end{array}\right)$ & $138 \pm 2$ & 88 \\
\hline \multirow[t]{3}{*}{$\mathrm{Pb}$} & $\left(\begin{array}{lll}1 & 1 & 1\end{array}\right)$ & $148 \pm 2$ & 63 \\
\hline & $\left(\begin{array}{lll}1 & 1 & 0\end{array}\right)$ & $163 \pm 3$ & 14 \\
\hline & $\left(\begin{array}{lll}1 & 0 & 0\end{array}\right)$ & $133 \pm 5$ & 97 \\
\hline \multirow[t]{3}{*}{ Sn } & $\left(\begin{array}{lll}1 & 1 & 1\end{array}\right)$ & $147 \pm 2$ & 84 \\
\hline & $\left(\begin{array}{lll}1 & 1 & 0\end{array}\right)$ & $170 \pm 2$ & 8 \\
\hline & $(100)$ & $140 \pm 1$ & 121 \\
\hline
\end{tabular}

\subsection{In strong-interaction metal/oxide systems}

A case in point is the $\mathrm{Al}-\mathrm{Al}_{2} \mathrm{O}_{3}$ system. Figs. 1 and 2 show our recent experimental results of the true contact angle and work of adhesion of molten $\mathrm{Al}$ on the different oriented

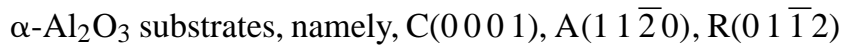
and polycrystal (PC), over a wide temperature range. (For

Table 4

Quantity of $\mathrm{O}^{2-}\left(\mathrm{NO}^{2-}\right)$ at $\mathrm{MgO}$ surfaces and the value of $\mathrm{NO}^{2-} / F$ [6]

\begin{tabular}{lll}
\hline Crystal face & $\begin{array}{l}N \mathrm{O}^{2-} \text { in } 1 \mathrm{~cm}^{2} \mathrm{MgO} \\
\text { surface }\left(\times 10^{-9}\right)\end{array}$ & $\begin{array}{l}\mathrm{NO}^{2-} / F \\
\left(\times 10^{-7} \mathrm{~mol} \mathrm{esu}^{-2}\right)\end{array}$ \\
\hline$\left(\begin{array}{lll}1 & 1 & 1\end{array}\right)$ & 2.18 & 6.0 \\
$\left(\begin{array}{lll}1 & 1 & 0\end{array}\right)$ & 1.33 & 4.5 \\
$\left(\begin{array}{lll}1 & 0 & 0\end{array}\right)$ & 1.88 & 9.0 \\
\hline
\end{tabular}

the definition of the true contact angle in the $\mathrm{Al} / \alpha-\mathrm{Al}_{2} \mathrm{O}_{3}$ system, refer to $[9,10]$.) It is apparent that the wettability and the adhesion are sensitive to the crystallographic orientation of $\alpha-\mathrm{Al}_{2} \mathrm{O}_{3}$. The adhesion is much stronger for the molten $\mathrm{Al}$ on the $\mathrm{R}$ and $\mathrm{A}$ surfaces than that on the $\mathrm{PC}$ and $\mathrm{C}$ surfaces, especially at relatively low temperatures. For the $\mathrm{C}$ face, due to the surface structural reconstruction from a $(1 \times 1)$ to a rotated $(\sqrt{31} \times \sqrt{31}) \mathrm{R} \pm 9^{\circ}$ structure (here, $\mathrm{R} \pm 9^{\circ}$ denotes rotation by $\pm 9^{\circ}$ ) at temperatures lower than $1200^{\circ} \mathrm{C}$ in the presence of $\mathrm{Al}$ [9], the contact angle increases and the work of adhesion decreases. With the increase in temperature, the contact angle and the work of adhesion on the R and A

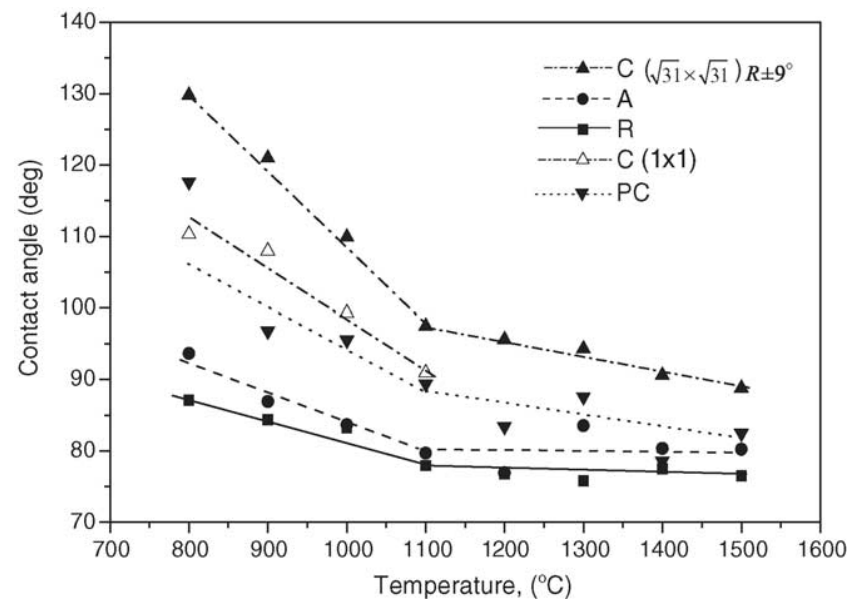

Fig. 1. True contact angle of molten $\mathrm{Al}$ on the different oriented $\alpha-\mathrm{Al}_{2} \mathrm{O}_{3}$ surfaces. 


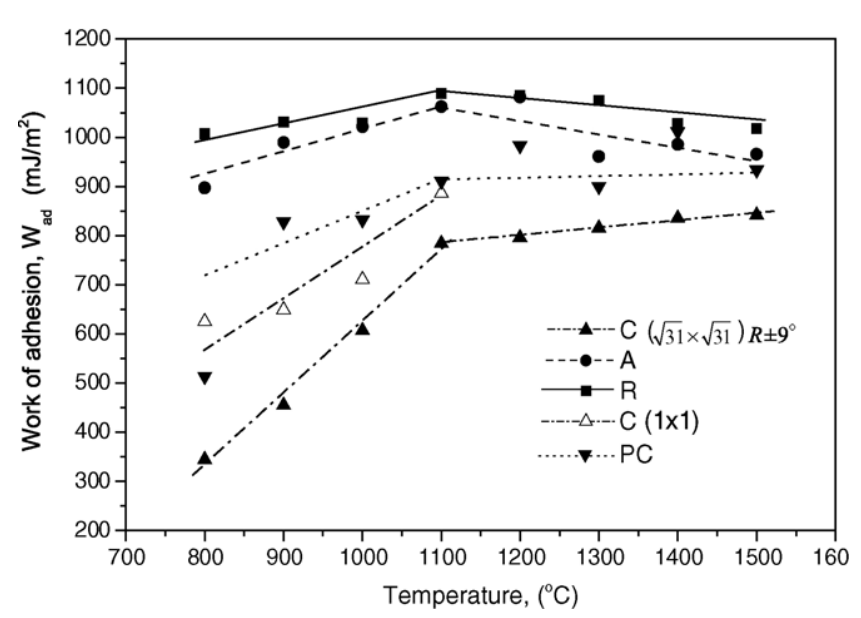

Fig. 2. Work of adhesion of molten $\mathrm{Al}$ on the different oriented $\alpha-\mathrm{Al}_{2} \mathrm{O}_{3}$ surfaces.

surfaces do not significantly change, while those on the C and PC surfaces show a substantial increase.

The dependence of the wettability and adhesion on the crystallographic orientation of the $\alpha-\mathrm{Al}_{2} \mathrm{O}_{3}$ substrates is related to the $\alpha-\mathrm{Al}_{2} \mathrm{O}_{3}$ surface structure and surface composition. It has been generally accepted that the $\mathrm{C}$ face is terminated with a single Al layer while the $\mathrm{R}$ and $\mathrm{A}$ faces are terminated with oxygen [11-14]. Also, the reconstructed $(\sqrt{31} \times \sqrt{31}) R \pm 9^{\circ}$ surface is an oxygen-deficient structure compared to the unreconstructed $(1 \times 1)$ surface $[12,14,15]$. On the other hand, in a recent first principles study on an $\mathrm{Al}\left(\begin{array}{llll}1 & 1 & 1\end{array}\right) / \alpha-\mathrm{Al}_{2} \mathrm{O}_{3}\left(\begin{array}{llll}0 & 0 & 0 & 1\end{array}\right)$ system, Siegel et al. [16] indicated that the primary interactions at the interface were $\mathrm{Al}-\mathrm{O}$ bonds. These bonds are very similar to the cation-anion bonds in the oxide bulk and are mainly ionic. Therefore, for the simplest consideration, the work of adhesion at the $\mathrm{Al} / \alpha-\mathrm{Al}_{2} \mathrm{O}_{3}$ interface can be expressed as

$W_{\mathrm{ad}}=\frac{N \mathrm{O}_{(\mathrm{s})}^{2-} \mathrm{Al}_{(\mathrm{l})}^{3+}}{R_{\mathrm{Al}_{(\mathrm{l})}-\mathrm{O}_{(\mathrm{s})}}}$

where $N$ is the number of $\mathrm{Al}_{(1)}-\mathrm{O}_{(\mathrm{s})}$ bond pairs and $R_{\mathrm{Al}(1)-\mathrm{O}(\mathrm{s})}$ is the distance between the most neighboring oxygen ions and aluminum ions at the interface (subscript 1 represents liquid state and s represents solid state). Obviously, $W_{\text {ad }}$ is essentially dependent on the number of $\mathrm{Al}_{(1)}-\mathrm{O}_{(\mathrm{s})}$ bonds, i.e., the quantity of $\mathrm{O}^{2-}$ on the top layer of the $\alpha-\mathrm{Al}_{2} \mathrm{O}_{3}$ surface if the distance, $R_{\mathrm{Al}(1)-\mathrm{O}(\mathrm{s})}$, is assumed to be the same for all the interfaces. Since the quantity of $\mathrm{O}^{2-}$ on the $\mathrm{Al}_{2} \mathrm{O}_{3}$ surfaces is in the order of $N(\mathrm{R})>N(\mathrm{~A})>N(\mathrm{C}$ $-1 \times 1)>N(\mathrm{C}-\sqrt{31} \times \sqrt{31})[10]$ (for the detailed surface structures of the C, A and R faces, refer to $[17,18]$ ) it is reasonable for the wettability and adhesion to be in the same order. The small difference between $W_{\mathrm{ad}}(\mathrm{R})$ and $W_{\mathrm{ad}}(\mathrm{A})$ is attributed to the additional contribution of the oxygen in the second layer of the A-face with a relatively large distance.

\section{General conclusions}

The nature of the substrate surface atoms, especially those at the top-layer, and their quantity or density play a decisive role in the interactions with the molten material atoms, thus determining the wettability and adhesion of the system.

In the systems composed of a single-element substrate but developing strong interactions with the molten material, the wettability and the adhesion on the less compact faces are better than those on the more compact faces. However, in the systems developing weak, van der Waals interactions at the liquid-solid interface, the opposite effect is displayed. In systems composed of a multi-component substrate, such as an oxide, the surface terminated atoms as well as their quantity play an important role in the determination of the wettability and adhesion of the system.

\section{Acknowledgements}

This work is supported by the NEDO International joint research grant and by Priority Assistance of the Formation of Worldwide Renowned Centers of Research-The 21st Century COE Program from the Ministry of Education, Sports, Culture, Science and Technology of Japan.

\section{References}

[1] Yu.V. Naidich, N.F. Grigorenko, V.M. Perevertailo, Interface and capillary phenomena in crystal growth and melting processes, J. Cryst. Growth 53 (1981) 261-272.

[2] C. Noguera, Physics and Chemistry at Oxide Surfaces, Cambridge University Press, Cambridge, 1996.

[3] K. Nogi, Y. Okada, K. Ogino, N. Iwamoto, Wettability of diamond by liquid pure metals, Mater. Trans. JIM 35 (1994) 156160.

[4] O. Dezellus, N. Eustathopoulos, The role of van der Waals interactions on wetting and adhesion in metal/carbon systems, Scripta Mater. 40 (1999) 1283-1288.

[5] K. Nogi, M. Nishikawa, H. Fujii, S. Hara, Wettability of diamond by liquid pure tin, Acta Mater. 46 (1998) 2305-2311.

[6] K. Nogi, M. Tsujimoto, K. Ogino, N. Iwamoto, Wettability of MgO single crystal by liquid pure $\mathrm{Pb}, \mathrm{Sn}$ and $\mathrm{Bi}$, Acta Metall. Mater. 40 (1992) 1045-1050.

[7] H. Takeda, M. Takeda, K. Nogi, K. Ogino, Surface observation of $\mathrm{MgO}$ single crystal with atomic force microscope and crystallographic orientation dependence of wettability of $\mathrm{MgO}$ by liquid metals, Mater. Trans. JIM 35 (1994) 466-472.

[8] R. Hultgren, Selected Values of the Thermodynamic Properties of Binary Alloys, American Society for Metals, Metals Park, OH, 1973.

[9] P. Shen, H. Fujii, T. Matsumoto, K. Nogi, Wetting of (0 0001$)$ $\alpha-\mathrm{Al}_{2} \mathrm{O}_{3}$ single crystals by molten Al, Scripta Mater. 48 (2003) 779-784.

[10] P. Shen, H. Fujii, T. Matsumoto, K. Nogi, The influence of surface structure on wetting of $\alpha$-alumina by $\mathrm{Al}$ in a reduced atmosphere, Acta Mater. 51 (2003) 4897-4906. 
[11] E.A. Soares, M.A. Van Hove, C.F. Walters, K.F. McCarty, Structure

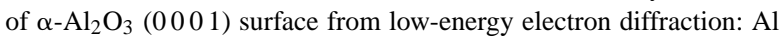
termination and evidence for anomalously large thermal vibrations, Phys. Rev. B 65 (2002) 195405.

[12] T.M. French, G.A. Somorjai, Composition and surface structure of the $(0001)$ face of $\alpha-\mathrm{Al}_{2} \mathrm{O}_{3}$ by low-energy electron diffraction, J. Phys. Chem. 74 (1970) 2489-2495.

[13] J. Guo, D.E. Ellis, D.J. Lam, Electronic structure and energetics of sapphire (0001) and (1 $\overline{1} 02)$ surface, Phys. Rev. B 45 (1992) $13647-13656$.

[14] M. Gautier, et al., $\alpha-\mathrm{Al}_{2} \mathrm{O}_{3}(0001)$ surface: atomic and electronic structure, J. Am. Ceram. Soc. 77 (1994) 323-334.
[15] G. Renaud, B. Villette, I. Vilfan, A. Bourret, Atomic structure of $\alpha-\mathrm{Al}_{2} \mathrm{O}_{3}\left(\begin{array}{llll}0 & 0 & 0 & 1\end{array}\right)-(\sqrt{31} \times \sqrt{31}) \mathrm{R} \pm 9^{\circ}$ reconstruction, Phys. Rev. Lett. 73 (1994) 1825-1828.

[16] D.J. Siegel, L.G. .Hector Jr., J.B. Adams, Adhesion, atomic structure, and bonding at the $\mathrm{Al}(111) / \alpha-\mathrm{Al}_{2} \mathrm{O}_{3}(00001)$ interface: a first principles study, Phys. Rev. B 65 (2002) 085415.

[17] P.W. Tasker, Surface of magnesia and alumina, in: W.D. Kingry (Ed.), Structure and Properties of $\mathrm{MgO}$ and $\mathrm{Al}_{2} \mathrm{O}_{3}$ Ceramics, The American Ceramic Society, 1984, pp. 176-189.

[18] V.E. Henrich, P.A. Cox, The Surface Science of Metal Oxides, Cambridge University Press, 1994. 